\title{
PROGRAMA DE EDUCAÇÃO AMBIENTAL PARA PROJETOS PRODUTORES DE ÁGUA: ESTUDO DE CASO DA BACIA HIDROGRÁFICA DO RIO CAMBORIÚ- SC, BRASIL
}

\author{
SANTOS, P. H. ${ }^{1 *} \&$ SCHWINGEL, P. R. ${ }^{1}$ \\ 1. Escola do Mar, Ciência e Tecnologia - Universidade do Vale do Itajaí (Univali) \\ *Corresponding author: santosph14@yahoo.com.br
}

\begin{abstract}
Santos, P. H. ${ }^{1}$ \& Schwingel, P. R. ${ }^{1}$ (2018). Programa de Educação Ambiental para Projetos Produtores de Água: Estudo de Caso da Bacia Hidrográfica do Rio Camboriú- Sc, Brasil. J. Aquat. Sci. Technol. 22(1). elSSN 1983-9057. DOI: 13262/bjast.v22n1. The Water Producer Program in Brazil is an initiative of the National Water Agency, created with the objective of reducing erosion and silting up of water bodies in rural areas. The Water Producer project, which adopts the public policy for Payment for Environmental Services, was implemented in the Camboriú River Basin, State of Santa Catarina, in 2013. A goal of the PA project is the creation of an Environmental Education Program. The present work presents in a systematized way a proposal of Environmental Education Program for Water Producer projects. The proposal includes meetings with rural and resident landowners, educational actions, development and distribution of teaching materials for dissemination, writing competitions and educational programs, educational blitz and partnerships with institutions that are not involved in the projects Water Producer.
\end{abstract}

Key Words: Environmental Education Program, Water Producer Project.

\section{INTRODUÇÃO}

A Educação Ambiental (EA), segundo Ministério da Educação do Brasil (2012), é parte da educação que tem a intenção de imprimir ao desenvolvimento individual um caráter social, relacionando o ser humano à natureza, de forma ética. A Política Nacional de Educação Ambiental, através da Lei n 9795/1999, afirma que a EA é entendida como processos pelo qual o indivíduo e coletivo constroem valores sociais, habilidades, atitudes, conhecimento e competências com objetivo de conservar o meio ambiente de forma sustentável (BRASIL, 1999). Para Reigota (2017), a educação ambiental deve favorecer e estimular uma nova aliança entre o ser humano e a natureza, possibilitando a convivência e sobrevivência entre as espécies com dignidade.

No Brasil, os projetos Produtor de Água (PA) consideram questões globais inter-relacionadas e dependentes umas das outras, sendo que paralelamente às ações de conservação, restauração e incentivos financeiros deve ser apresentada uma proposta social que contribua com as políticas de Educação Ambiental. Essa proposta tem como objetivo, além da recuperação ambiental, a transformação social e a ressignificação da natureza para as comunidades das bacias hidrográficas estratégicas (ANA, 2012).

Em 2013, inspirada pela Agencia Nacional de Águas (ANA) e outras experiências internacionais, foi criado o projeto Produtor de Água (PA) na Bacia Hidrográfica do Rio Camboriú (BHRC), Estado de Santa Catarina. A área de intervenção do projeto PA, localizada no curso superior do rio Camboriú, é de aproximadamente $138 \mathrm{~km}^{2}$ (Dacol, 2011), que corresponde a cerca de $70 \%$ da área de toda da bacia. O projeto PA tem como meta, além do aumento da quantidade e qualidade da água, a implantação de um Programa de Educação Ambiental. Santos (2018), estudando o PA na BHRC, estabeleceu indicadores para avaliar sua eficácia. Entre esses indicadores, o programa de Educação Ambiental teve uma eficácia de $40 \%$, representado a designação "não existe, mas tem ações pontuais realizadas nas escolas". A criação e implementação de programas de EA são importantes para sensibilizar e engajar a sociedade nos projetos PA, portanto, é uma ferramenta que deve ser desenvolvida e aplicada nestes projetos. Antunes (2014) sugeriu a implantação de ações permanentes de Educação Ambiental nos projetos PA, como forma de mobilização continua junto aos proprietários rurais. Ao mesmo tempo, essas ações podem incentivar a adesão de novos proprietários aos projetos PA.

ABHRC, localizada nos municípios de Balneário Camboriú e Camboriú, drena uma área de aproximadamente $200 \mathrm{Km}^{2}$ (Figura 1), sendo que cerca de 90\% das nascentes encontram-se no município de Camboriú (Antunes et al., 2007). A bacia sofre pressão de diversos setores econômicos, destacando agricultura irrigada, pesque-pague e mineração na porção superior, e setor imobiliário, construção civil e turismo na porção próxima da foz (Urban, 2008). O objetivo deste estudo é apresentar uma proposta de Programa de Educação Ambiental para projetos Produtores de Água, tendo como estudo de caso o projeto Produtor de Água da Bacia Hidrográfica do Rio Camboriú. 
Figura 1- Localização da Bacia Hidrográfica do Rio Camboriú Município de Camboriú e Balneário Camboriú - Santa Catarina.
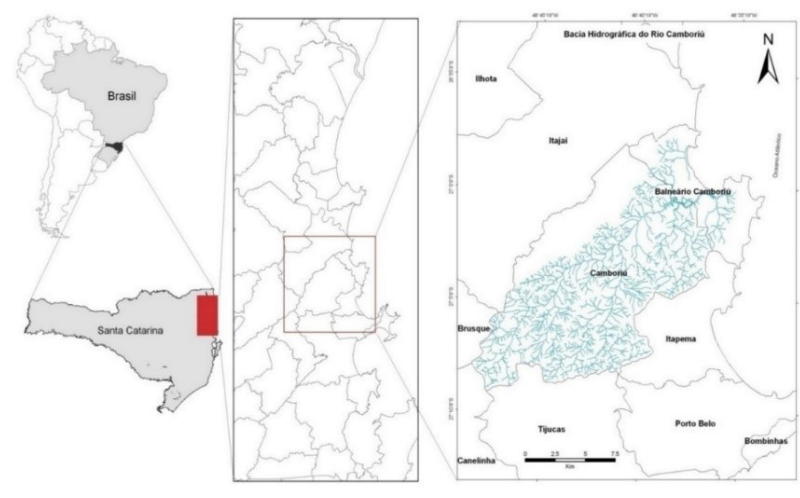

Fonte: Emasa, 2009.

\section{MATERIAIS E MÉTODOS}

\section{Programa de Educação Ambiental (EA)}

Para aumentar a eficácia dos projetos PA e cumprir parte de suas metas é apresentada uma proposta de Programa de Educação Ambiental, considerando estratégias e instrumentos para sensibilizar e orientar os usuários da bacia na preservação ambiental através do ensino, pois segundo Moran (2007), a educação é caracterizada pela soma de todos os processos de transferência do conhecimento, podendo ser repassada de maneira formal ou informal através de pessoas, grupos ou instituições.

\section{a) Orientações sobre a Educação Ambiental}

A cartilha, como instrumento de educação ambiental, deve apresentar conteúdo de fácil leitura e entendimento dos anseios do público-alvo, i.e. proprietários rurais, moradores e visitantes da bacia. Conceitos-chave devem ser considerados na sua elaboração, a saber: educação comum e ambiental; bacia hidrográfica, localização da bacia, Pagamento por Serviços Ambientais (PSA), Programa Produtor de Água, projeto Produtor de Água. Em relação aos projetos PA, aspectos de quando, como, porque foi criado, principais metas, situação atual e a importância da educação ambiental para o mesmo, podem fazer parte do conteúdo desde material didático. A cartilha pode ser elaborada por instituição de ensino, parceiros do projeto PA, profissional da área ambiental ou pelos membros do Grupo Gestor (Santos \& Schwingel,2017). Esse instrumento pode ter o formato digital, entretanto, é essencial o impresso em material reciclado, representando o conceito de sustentabilidade (Figura 2).
Figura 2- Exemplos de materiais de divulgação do Programa de Educação Ambiental e do projeto Produtor de Água da Bacia Hidrográfica do Rio Camboriú-SC.

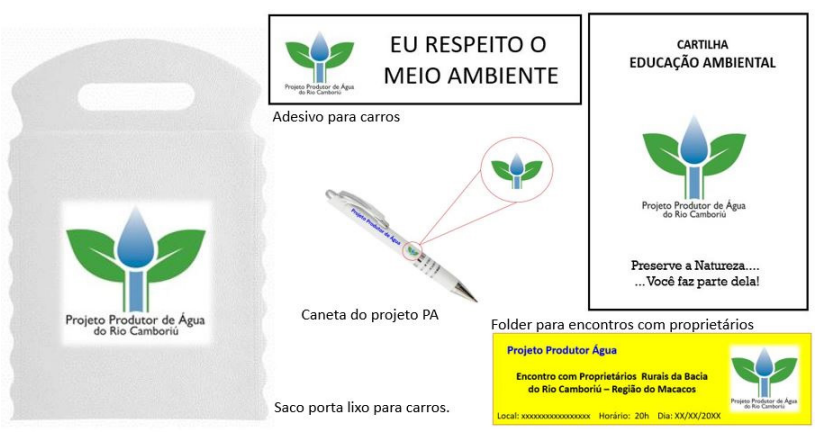

b) Encontros com os Proprietários Rurais

Os encontros com proprietários rurais e moradores das áreas de atuação dos projetos PA devem ter dois focos: a educação ambiental, com objetivo de sensibilizar os usuários das bacias sobre a importância da preservação; e divulgar os projetos PA, que inclui preservação, recuperação das nascentes e vegetação dentro e fora das Áreas de Preservação Permanentes (APPs). Uma periodicidade dos encontros deve ser mantida, sendo realizados em diferentes regiões da área de atuação dos projetos PA.

Relatos de proprietários rurais que aderiram aos projetos PA são fundamentais nos encontros, pois podem orientar e sensibilizar os interessados, contribuindo para novas adesões. Para divulgação dos encontros, meios de comunicação como rádio, TV, anuncio em reuniões de associações e instituições, folders entregues aos moradores e proprietários locais (Figura 2), bem como cartazes fixados em locais de maior circulação do público-alvo, podem ser utilizados. A distribuição da cartilha nestes encontros possibilita o acesso a informação, podendo ser utilizada como fonte de consulta para possíveis dúvidas.

\section{c) Ações Educacionais}

Envolver as comunidades escolares situadas nas regiões de atuação dos projetos PA é essencial para um programa de EA e também pode auxiliar na divulgação dos projetos PA, pois os gestores, professores e principalmente os alunos são potenciais multiplicadores das ideias de gestão e proteção ambiental. Por este motivo é importante o desenvolvimento de ações educacionais como, teatro, desenho, atividade lúdica, contação de história e outras, que motivem esse público-alvo.

Para Sauvé (2005), a educação ambiental não é uma ferramenta para solucionar os problemas de gestão do meio ambiente, mas uma dimensão impor- 
tante da educação fundamental, visando estabelecer relação entre o indivíduo com ser social e o meio ambiente. Portanto, formar os discentes, futuros tomadores de decisões, para que compreendam seu papel na sociedade e para com o meio ambiente é essencial para o sucesso de Programas de Educação Ambiental. Assim sendo, é necessário a realização de ações mais amplas, como a construção de política públicas votadas para a educação ambiental municipais e estaduais nas bacias hidrográficas, que norteiem e sensibilizem os alunos das redes municipais, estaduais e particulares quando aos seus deveres para com o meio ambiente.

No início do Programa de Educação Ambiental, as primeiras instituições escolares contempladas deverão estar inseridas nas áreas de atuação dos projetos PA. Antes de definir os colaboradores e conteúdo a serem ministrados é aconselhável visitar cada instituição e observar o público-alvo, estabelecendo estratégias para as apresentações. Instituições parceiras dos projetos $\mathrm{PA}$, que desenvolvem atividades de educação ambiental, podem colaborar na execução das ações educacionais. Para os anos posteriores, além de manter o foco principal nas instituições escolares na área de atuação dos projetos PA, é necessário estender o programa para outras áreas da bacia. A responsabilidade de definir as instituições a serem contempladas com as ações educacionais deve ser de responsabilidade do Grupo Gestor de cada projeto Produtor de Água.

d) Materiais Didáticos de Divulgação e Locais de Distribuição

Utilizando o conceito de sustentabilidade, o Programa de EA deve procurar desenvolver e ou adquirir materiais, se possíveis sustentáveis, para divulgar tanto o programa como os projetos PA. Stols e Vaz (2009) destacam que a educação ambiental tem como objetivo demostrar que o ser humano tem a capacidade de propor mudanças ao seguir caminhos que o leve a um mundo socialmente mais justo e sustentável.

Nas ações educacionais, o uso de materiais como a cartilha em papel reciclado, lápis feitos com madeira de reflorestamento, canetas e réguas de plástico reciclado, bloco de anotação com mensagens educativas e logotipo dos projetos PA, podem ser estratégias para divulgar o Programa de EA e os projetos PA. Nos encontros semestrais com os proprietários e moradores locais da área de atuação dos projetos PA, podem ser distribuídos cartilhas, canetas, blocos de anotações, porta-lixos e adesivos para carros (Figura 2).

Os materiais para divulgar, orientar e sensibi- lizar os usuários das bacias com relação a educação ambiental e os projetos PA, além de ser distribuídos nas ações educacionais, encontros e blitzes, também podem estar disponíveis em pontos específicos, como bancos, prefeituras, Câmara de Vereadores, Câmara de Dirigentes Lojistas, universidades, associações, entre outros. A divulgação do Programa de Educação Ambiental e dos projetos PA devem alcançar o maior público possível.

\section{e) Concurso de Redação e Programetes}

A percepção ambiental reflete a capacidade interpretativa do ser humano pautadas em sentimentos, vivência, experiência e observações que podem ser aplicadas nas relações entre o ser humano e ao meio ambiente, (Dias et al., 2016). Neste contexto, a elaboração de instrumentos como "redação" ou "programetes" podem ser empregados para que o discente dos ensinos fundamental e médio, expressem sua relação com o meio ambiente.

No início do ano letivo, concursos de redação e programetes, com os respectivos regulamentos, podem ser apresentados ás unidades escolares através de folders, cartazes, rádio, TV, mídias sociais e outros meios. Para os ganhadores, i.e. discentes e instituições de ensino, devem ser oferecidos prêmios como estratégia de incentivo a participação de um maior número de interessados. Os resultados dos concursos de redação e programetes podem ser utilizados como matérias didáticos de divulgação do Programa de Educação Ambiental e dos projetos PA.

\section{f) Blitz Educativa Ambiental}

Informar e ensinar os motoristas, ciclistas, pedestres e usuários da bacia sobre os principais aspectos da educação ambiental é fundamental para Programas de EA, pois a educação é um meio para transformar a sociedade em que vivemos. Esta mudança de conceitos pode ser implementada através de blitz educativa ambiental. Este instrumento pode ser realizado periodicamente em datas comemorativas ligadas ao meio ambiente.

Os locais para a realização as blitzes devem ter características específicas, como pontos de entradas e saídas das áreas de atuação dos projetos PA e locais com grande circulação de usuários da bacia hidrográfica. As blitzes podem ser realizadas com apoio de instituições parceiras dos projetos PA, alunos de graduação de curso que envolvam a área ambiental, bem como da Polícia Ambiental. Durante o evento, a distribuição de materiais didáticos e de divulgação podem ser utilizados para conscientizar os usuários da região de atuação dos projetos PA. 


\section{g) Parcerias com outras Instituições}

A colaboração de instituições não parceiras também é importante para o Programa de Educação Ambiental e projetos $\mathrm{PA}$, pois podem possuir infraestrutura e logística para a realização dos encontros, blitzes e nas ações educacionais. Instituições como universidades, faculdades, associações, Serviço Social do Comércio, escoteiros, Guarda Municipal e a Polícia Militar podem ser convidadas para o desenvolvimento e implementação do Programa de Educação Ambiental.

\section{CONCLUSÃO}

A Educação Ambiental associada aos projetos Produtores de Água pode dispor de diferentes instrumentos ou estratégias para serem usadas em conjunto ou de forma isolada dentro de um cronograma de longo prazo, considerando que os projetos PA, baseado no PSA, não possuem prazos limitados para seu desenvolvimento. Ao mesmo tempo, é necessário o desenvolvimento dos Programas de EA junto aos projetos PA, pois é fundamental ensinar as diferentes gerações e futuros tomadores de decisões, a importância dos conceitos de sustentabilidade ambiental na bacia hidrográfica. Em adição, os programas de Educação Ambiental devem considerar as características da cultura local onde os projetos Produtor de Água são desenvolvidos.

\section{REFERÊNCIAS}

ANA, Agência Nacional de Águas. 2012. Projeto Detalhado, Produtor de Águas (SC). Disponível em: http://produtordeagua.ana.gov.br. Acesso em:17 jul. 2018.

Antunes, P.P. 2014. Pagamento por Serviços Ambientais: O projeto Produtor de Águas na Bacia Hidrográfica do Rio Camboriú como Instrumento de Conservação Ambiental no Município de Camboriú (SC). Tese de Doutorado. Universidade do Vale Itajaí. 162p.

Antunes, A.; Schwingel, P.R.; Burliga, A.L.M. \& Urban, S.R. 2007. Composição do fitoplâncton na bacia hidrográfica do rio Camboriú (SC Brasil) durante o verão de 2005. Brazilian Journal of Aquatic Science Technology, 11(2): 33-43.

BRASIL. Lei ${ }^{\circ} 9795$ de 27 de abril de 1999. Dispõe sobre Educação Ambiental, Institui a política Nacional de Educação e dá outras providencias. Brasília: Impresa Oficial, 1999. Acesso em: 12 jul. 2018.

BRASIL. Resolução n² 2, de 15 de junho de 2012. Ministério da Educação, Conselho Nacional de Educação, Conselho Pleno. Estabelece as Diretrizes Curriculares Nacionais para a Educação
Ambiental. Disponível em < http://mobile.cnte.org. br:8080/legislacao-externo/rest/lei/89/pdf> Acesso em: 12 julho 2018.

Dacol, K.C. 2011. Pagamento por Serviços Ambientais: Critérios de Valoração do Projeto Produtor de Água do Rio Camboriú. Monografia. Centro de Ciências Exatas e Tecnologia - Pontifícia Universidade Católica do Paraná. 46p.

Arana, A.R.A \& Bizarro, L.M.C.E. Educação Ambiental e Política Ambiental Integrada: O Papel das Universidades. 2016. In: Dias, L.S.; Carpi Junior, S.; Leal, A.C. (orgs.). Educação Ambiental, conceitos, metodologias e práticas. 1ed. Tupã. SP., 154-168pp.

Moran, J.M.R. 2007. A educação que desejamos: novos desafios e como chegar lá. Papirus, Campinas, $174 \mathrm{p}$.

Reigota, M. 2017. O que é educação ambiental. Brasiliense, São Paulo, 107p.

Santos, P.H. 2018. Avaliação da Eficácia do Projeto Produtor de Água na Bacia Hidrográfica do Rio Camboriú (SC). 148f. Dissertação de Mestrado (Ciência e Tecnologia Ambiental). Universidade do Vale Itajaí.

Santos P.H. \& Schwingel P.R. 2017. Proposta para procedimentos de vistoria de projetos produtor de água: bacia hidrográfica do rio camboriú SC, Brasil. Brazilian Journal of Aquatic Science Technology, 21(1): 1-3.

Sauvé, L. 2005. Educação Ambiental: possibilidades e limitações. Revista Educação e Pesquisa. São Paulo, 31(2): 317-322.

Stolz, P.V.\& Vaz, M.R.C. 2009. Compreensão dos separadores de resíduos acerca do seu trabalho com o meio ambiente. Revista Eletrônica do Mestrado em Educação Ambiental, RS. 22: 234-246.

Urban, S.R. 2008. Uso do Solo na BHRC (SC) e sua Influência sobre a Qualidade da Água. 100f. Dissertação de Mestrado (Ciência e Tecnologia Ambiental). Universidade do Vale Itajaí. 